\title{
Interactive Computer-Centered Instructions for Science and Engineering Education
}

\author{
Mohammad A. Matin \\ Department of Electrical and Computer Engineering, University of Denver, Colorado, USA \\ Email:mmatin@du.edu
}

Received March 28 ${ }^{\text {th }}$, 2012; revised April 25 ${ }^{\text {th }}$, 2012; accepted May $10^{\text {th }}, 2012$

\begin{abstract}
Both the formal and informal cooperative learning methods are proven pedagogical tools that provide the context for engaging students in reflective judgment and consultation. The cooperative method pays close attention to the multiple learning styles of students participating in the classroom project. Our engineering program's goal is to expose students majoring in engineering (electrical, computer and mechanical) to a positive interdependence, face-to-face interaction, development of interpersonal skills and individual accountability. We introduces the use of Blackboards and clickers together to enhance cooperative learning aimed at educating students to succeed in today's global economy. As such, classroom instruction and group projects were assigned to foster an environment that maximized the use of computers, took advantage of information and resources available on the internet and Blackboards, and nurtured cooperative learning among groups. This paper describes a method to create a learner-centered, cooperative environment, which will engage students, give positive interdependence, face-to-face interaction, and will help them to develop interpersonal skills and individual accountability in better understanding, critical thinking and judgment, all of which are necessary skills to succeed in twenty first century economy. This teaching method already impacted hundreds of students from fall, winter and spring, 2007 to spring 2011 and will impact thousands of students in the future. At the end of the courses outcomes were evaluated using developed questionnaires using Clicker response system. To answer one of the questions, "I wish the professors in my other classes use the clicker”, $72.1 \%$ strongly agree or agree, $18.3 \%$ disagree and $9.7 \%$ strongly agree. To answer another question, "The use of clickers in techhnology-21 class improves my ability to learn the material”, $88.3 \%$ strongly agree or agree, $9.6 \%$ disagree and $2.1 \%$ strongly agree. According to the results obtained from the questionnaire, students heavily benefited from the clicker system. The assessments were done anonymously.
\end{abstract}

Keywords: Clicker; Engineering Education; Pedagogy; Blackboard; Cooperative; Face-to-Face Interaction

\section{Introduction}

In 1995, Robert Barr and John Tagg (1995) observed a paradigm shift in American education-from the traditional "Instruction Paradigm" to the "Learning Paradigm." Reviews of models developed in the Education field reveal that a quiet but exciting revolution is taking place in the way education is delivered following John Dewey's seminal works published several decades ago (1933, 1944). In 2001 Johnson \& Johnson (2001) reported that there are three basic ways students can interact with each other as they learn. They can compete to see who is "best", they can work individualistically toward a goal without paying attention to other students, or they can work cooperatively with a vested interest in each other's learning as well as their own.

A majority of students are not able to stay focused during a lecture for more than 30 minutes. After about 15 or 20 minutes, their attention starts to drift for a bit, and by the end of the lecture they are not able to absorb much or in some cases, any of the information. According to McKeachie (1999), “a classroom research study showed that immediately after lecture students recalled $70 \%$ of the information presented in the first 10 minutes and only $20 \%$ of that from the last 10 minutes". Students' attention can be maintained throughout a class session by peri- odically giving them something to do. According to Johnson et al. (1998), Felder (1994), Meyers et al. (1993), and Bonwell et al. (1991), many different activities can serve this purpose of which the most common is the small-group exercise also called the active learning exercise. The basic exercise includes: 1) responding to questions; 2) problem solving; 3) explaining written material; 4) analytical, critical, and creative thinking; 5) recalling prior material; 6) summarizing.

"Cooperative learning is instruction that involves students working in teams to accomplish an assigned task and produce a final product under conditions that include the following five elements”, Felder (1994):

1) Positive interdependence;

2) Individual accountability;

3) Face-to-face interaction;

4) Appropriate use of teamwork skills;

5) Regular self-assessment of team functioning.

We adapted an interactive computer centered cooperative learning experience using two dimensions. These are the Radio Frequency based clicker response system and the Blackboard (Bb). This philosophy of engaging students with active learning in a class room environment gave positive experiences that motivated them as life-long learners. 
The common vision that all faculties involved from the department of Electrical and Computer Engineering and Mechanical and Materials Engineering share in this project is to create a learner and computer-centered environment, which engages students in critical thinking and judgment necessary to motivate in current technology. Carefully chosen multiple-choice conceptual questions are posed to students during lecture segments. The students are then encouraged to discuss these questions cooperatively with their members and ultimately convey their answers to the instructor using clicker in real time. The lecturer then devotes some time to a resolution of the issues raised by the students' responses.

\section{About Clicker}

"In 1997, the Physics department at the University of Illinois embarked on a major reform of all of its 33 introductory classes”, Scott (2007). Their goal was to integrate all aspects of a course using interactive engagement methods based on physics education research in a team teaching environment. The major change to their lectures was to include active learning segments. These segments were patterned after the concept tests introduced at Harvard University. We have taught two different levels of introductory physics at Harvard using this strategy and have found that students make significant gains in conceptual understanding (as measured by standardized tests) as well as gaining problem solving skills comparable to those acquired in traditionally taught classes. Dozens of instructors at other institutions have implemented Peer Instruction with their own students and found similar results”, Mazur group (2011). Carefully chosen multiple-choice conceptual questions are posed to students in these segments. The students are then encouraged to discuss these questions with their neighbors and ultimately convey their answers to the instructor. The lecturer then devotes some time to a resolution of the issues raised by the students' responses.

Initially, the students register their votes by using flashcards. The quantitative aspects of this system is limited, but, more importantly, the students' votes are not unknown. In the intervening years, they experimented with various systems to record the students' votes, including a wired system and an infrared-based wireless system. They encountered the problems using these systems that led them to develop "i-clicker". This development took two years and was generously supported by the Provost's Initiative on Teaching Advancement, the Educational Technology Board, the College of Engineering, and the Department of Physics at the University of Illinois.

In 2005, Hayden-McNeil Publishing acquired i-clicker. "The acquisition adds to Macmillan's portfolio of leading higher education publishers which includes Bedford St. Martin's, W. H. Freeman, Worth Publishers, and i-clicker, a leading provider of classroom response systems, Macmillan News (2011)”.

There is overwhelming evidence that students learn more if they actively participate in their learning, Johnson et al. (1991, 1998) and Lyman (1998). The use of a personal response system, also known as clickers, in lecture classes is becoming widespread at a large number of universities. I-clicker (2011), the most flexible and most reliable classroom response system, requires no hardware installation, eliminates the frustrating log-in procedure, works with any presentation application, includes a built-in LCD screen, and can be formatted according to style preferences, Interactive Teaching DVD (2007).
These devices allow students to respond to questions developed by the instructor and enable the instructor to use a number of activities that promote active learning. Initially, the clicker was incorporated into the general chemistry course and all three quarters of the organic chemistry sequence in Denver University. A trial was performed in the organic chemistry course during the winter quarter of 2006. A more extensive program was used during the second quarter of organic chemistry in the spring 2007. Because the careful design of questions that focus on key concepts is of critical importance to the use of clickers, considerable effort has been devoted to this, during the summer. After successfully completing a project funded by the Center for Teaching and Learning at the University of Denver, results were published in an international Conference in 2008 (Matin et al., 2008).

The clicker is ideal for encouraging class participation in any size classroom from small enrollments to large enrollment. Harvard University physicist Eric Mazur demonstrates the use of Peer Instruction and Just-in-Time Teaching - two innovative techniques for lectures that use in-class discussion and immediate feedback to improve student learning. These techniques are now being used successfully in many disciplines. All incoming engineering students have to buy Turning Technologies clickers, Turning Technologies (2011) for all four years of the degree program.

\section{Description of the Project}

The project involves the introduction of cooperative learning non-traditional methods aimed at educating students to succeed in today's global economy. As such, classroom instruction and group projects assigned foster an environment that maximizes the use of computers, takes advantage of information and resources available on the internet and Blackboards, and nurtures cooperative learning among groups. Real-world technological situations were presented. Students had the opportunity to actively interact with partners and faculty using blackboard.

The following tools in Blackboard were used to facilitate cooperative learning.

\section{Blackboard Tests \& Surveys}

Incorporate surveys (anonymous) or tests (graded) into cooperative learning activities or to solicit feedback about cooperative learning activities. Use surveys for peer rating of team members. Instructors can develop online tests or quizzes in Blackboard that students complete as a group or a team.

\section{Group Pages}

Creating Blackboard Groups can give students tools to collaborate online on cooperative learning projects. Blackboard groups have their own self-contained email, discussion groups, collaboration and file exchange area.

\section{Group Selection}

Use Advanced Group Manager to randomly assign students to their group or to create groups.

\section{Email}

Blackboard groups have their own self-contained email. Emails 
can be sent to individual users or to the entire group. Emails sent from within Blackboard are sent to the student's DU email address.

\section{Collaboration Tools}

The collaboration tools in Bb provide a synchronous communication area that enables users to participate in online collaborations with instructor and students. The collaboration area includes a Lightweight Chat and Virtual Classroom.

\section{Lightweight Chat}

Communication tool that allows students to participant in real time text-based discussions. Lightweight chat works similar to instant messenger.

\section{Virtual Classroom}

The Virtual Classroom consists of all the functionality included in the Lightweight Chat plus it includes a whiteboard and other features that may be used during online collaboration sessions.

\section{File Exchange}

File Exchange is a tool that the students can use to exchange files for group projects they are collaborating on. Instead of exchanging files via email, students can send and pickup files from the group tools area in Blackboard.

\section{Wiki}

Wiki is a collaborative tool which has been licensed as an add-on to Blackboard. The wiki tool was developed by a company called Learning Objects. The license also includes a course Blog tool. Instructors can assign students the task of creating a collaborative website, or wiki, within the course management environment and the instructor can assess each student's individual contributions to the sites. Each student can add content, edit others' contributions, and reformat layout as he desires, but a full history of the revisions is maintained and accessible. Determining what and how much to add or revise is part of the group process.

\section{Discussion Board}

The Discussion Board is a communication tool that allows students and instructors to participate in online discussions without requiring all class participants to be online at the same time. Conversations are grouped into Forums and Threads that contain a main posting and all related replies. Bb groups or teams can have online discussions between group members and then share a summary of their group discussions in the main course discussion board.

The discussion board was used as a Group discussion Board: we provide a Group Discussion Board to any group. It was only accessible to the members of the group. The instructor and the group members can create forums in the Group's Discussion Board. Group members can change the name of, but not delete, a forum the Instructor has set up.

We set up as gradable Discussion board and each gradable forum creates a grade book column that only the members of the group could see (i.e. a group's members do not see other group's discussion grade center columns). Following are the description, grading rubrics, assessment criteria of discussion board posted in the Blackboard.

\section{Discussion Board Usage}

The online discussion board is this course's equivalent of in-class participation. Participation includes students posting their own thoughts and responses to texts, videos, and other assignments. It also includes students posting their responses to other students' thoughts and responses. Discussion boards are not a series of disconnected monologues - they are a rich, evolving set of dialogues.

Please plan to check the Bi-weekly discussion board threads several times and respond to new posts or reply to post responses frequently. For each discussion board assignment, you should post your own response and respond to other students' posts. Always use proper scientific terms.

\section{Assessment of Students' Discussion Board Posts Will Consider}

- The degree to which the student demonstrates his/her understanding of the question or prompt, and the underlying or broader issues associated with the question.

- How well the student brings course materials into his/her response, including specific examples that may help to solve the marketing problem.

- Whether the student makes effective reference to outside (non-class) materials that may relate to the question, or considers the question from a different perspective.

- How thoughtfully and seriously the student replies to other students' responses to his/her post.

- Clear, concise writing style, with effective paragraphing, minimal spelling errors, and appropriate grammar.

- Use Equation Editor.

- Give references.

\section{Assessment of Students' Discussion Board Responses Will Consider}

- How effectively the student engages with the student response to which (s)he is responding, including referring to the posting student by name and reflecting on specific points in the original post.

- Clear, concise writing style, with effective paragraphing, minimal spelling errors, and appropriate grammar.

- Use proper scientific terms.

\section{Discussion Grading Rubric}

\section{Excellent/Satisfactory/Unsatisfactory}

Response to Discussion Question (maximum 5 points) Response demonstrates a thoughtful analysis of the question and provides at least three supporting examples (5 points) Response offers an opinion with 1 - 2 supporting examples (3 points) Expresses opinion without supporting examples (1 point) Responses to Networking Postings (maximum 5 points) Thoughtful response to posting, including comments and questions that facilitate further discussion (1 point per response) Limited or vague response to posting that leaves little opportunity for continued discussion (.5 point per response) Expresses simple agree- 
ment or disagreement without discussion (0 points).

In addition, they had the opportunity to actively participate in the class room using Radio Frequency based clicker. Figure 1 depicts the model central to the project.

\section{Educational Objectives Achieved}

The following educational objectives were achieved:

1) Introduced cooperative-based instruction in Science and Engineering courses;

2) Promoted retention of critical theories and technological concepts;

3) Provided "relevant" education that allowed students to be effective in active learning;

4) Fostered interactive learning and real time feedback using clicker;

5) Nurtured an active learner-centered cooperative environment;

6) Encouraged maximum use of computer-centered learning using internet and blackboard;

7) Implemented a learner and computer-centered cooperative environment by adapting the curriculum to accommodate multiple learning styles;

8) Developed the reflective judgment skills of students in current and future technology;

9) Promoted an interdisciplinary perspective in a cooperative manner.

By participating in this new teaching method, students achieved the following learning outcomes:

1) The student demonstrated effective understanding of theoretical and practical concepts presented in the course;

2) The student identified the problem, research and analyzed pertinent data/information, and evaluated alternative courses of decisions/actions available;

3) The student decided the most appropriate action in the twenty first century technology applications;

4) The student appreciated the complexities involved in working a cooperative environment; tion.

5) The student visualized the science and technology applica-

\section{Results and Discussion}

After a successful clicker workshop in the summer of 2007, Computer Centered Cooperative instructions were implemented in various departments of Natural Science and Mathematics division and School of Engineering and Computer Science, at the University of Denver. Science and engineering faculty showed an enormous interest in implementing the clicker based teaching to enhance the student's learning skills. As examples,

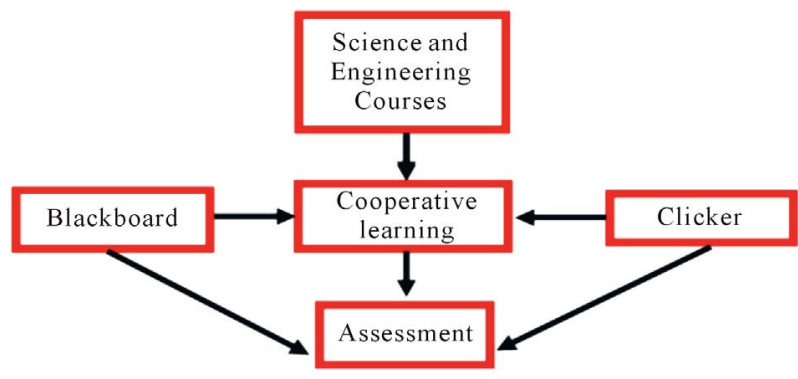

Figure 1.

The model. here are some results from three courses such as Technology-21, Optoelectronics and Optical networking. In optoelectronics and Optical Networking classes cooperative learning was facilities using the following tools from Blackboard in addition to use the clicker during class.

- Blackboard Tests \& Surveys.

- Email.

- File Exchange.

- Wiki.

- Discussion Board.

Both clicker and Blackboard surveys were used for the course assessment. In Optoelectronics and Optical Networking class related videos were posted in the assignment section of the Blackboard. A graded and non graded Discussion Forum was added in the Group discussion area, 95\% to 98\% student participated in the graded discussion compare to $65 \%$ to $70 \%$ in non graded discussion. Incentives are very important and attention is needed during the developing of course materials. An incentive for faculty is also important to participate in the new programs, such as salary supplements or stipends. The Center for Teaching and Learning (CTL) provides half stipend for developing a pilot course and other half for implementing the course. Assessments were performed after four weeks and ten weeks of quarter system. Both assessments are in very close agreement with only $5 \%$ difference.

This teaching method already impacts hundreds of students from fall, winter and spring, 2007 to spring 2011 and will impact thousands of students in the future. This new teaching method developed higher-order thinking competencies, promoted collaborative learning, and improved communication skills and student instant feedback. At the end of the courses outcomes were evaluated using developed questionnaires using Clicker response system.

Results of assessment for Technology-21 Class using Clicker are presented below:

The assessment questions for Technology-21 class were:

1) The use of Clickers in Technology-21 improved my ability to learn the material;

2) The frequency of the use of Clickers in Technology-21 was just right;

3) I wish the professors in my other classes would use the Clicker;

4) The use of the Clicker in Technology-21 encouraged me to attend lectures;

5) The use of Clickers in Technology-21 helped me understand energy, its benefits and problems.

The assessments were done anonymously and results are shown below in a pie-chart format (Figures 2-6):

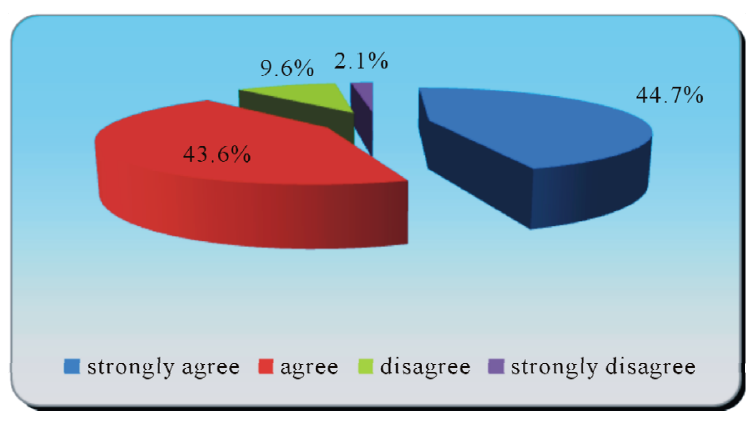

Figure 2.

The use of Clickers in Technology-21 improve my ability to learn the material. 


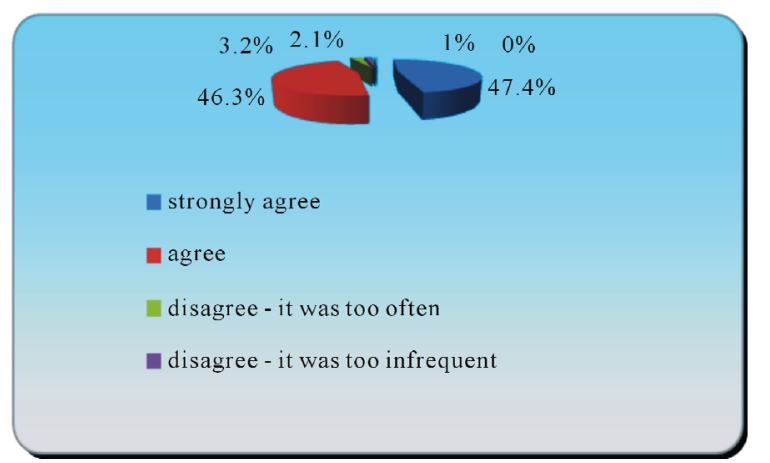

Figure 3.

The frequency of the use of Clickers in Tech-21 was just right.

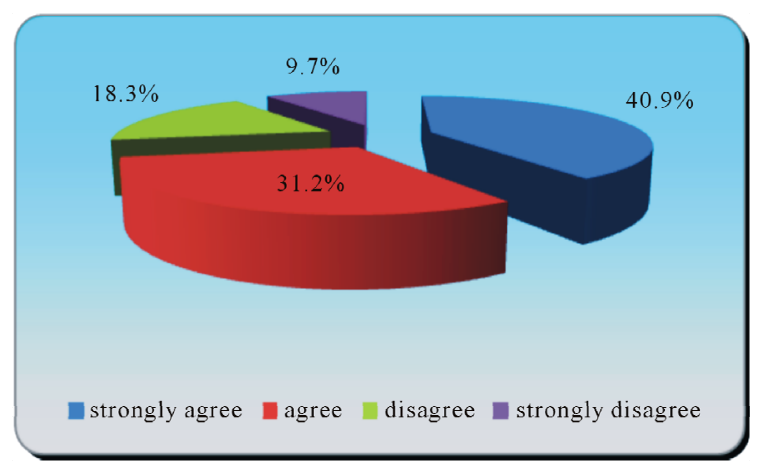

Figure 4.

I wish the professor in my other classes would use the Clicker.

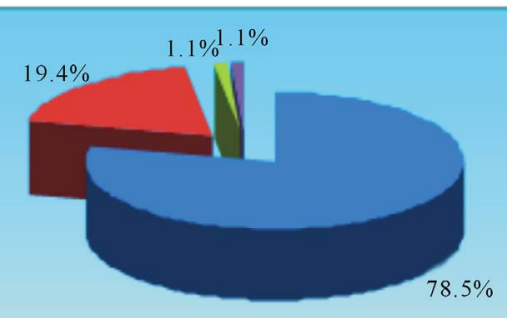

| strongly agree || agree || disagree | strongly disagree

Figure 5.

The use of the Clicker in Tech-21encouraged me to attend lectures.

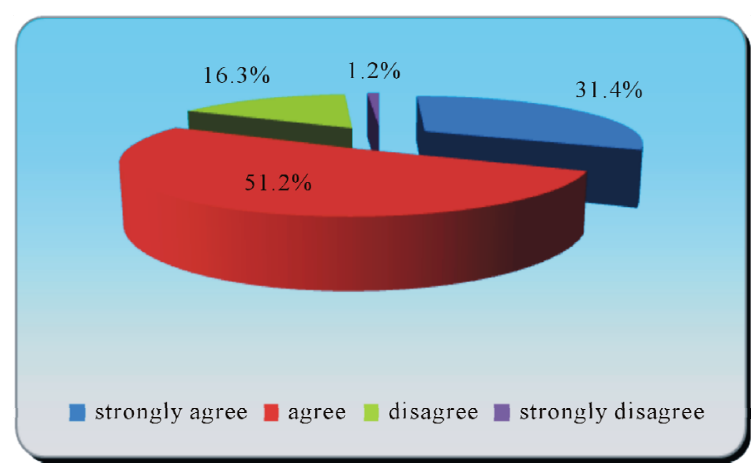

Figure 6.

The use of Clickers in Tech-21 helped me to understand the subject materials.
Through the input of students, majority believed that the clicker had not only helped them understand the course materials, but liked the frequency of the use, and believed it encouraged participation.

\section{Acknowledgements}

Author is acknowledging Office for Teaching and Learning (OTL), University of Denver for their funding and science and engineering faculty who participated in the clicker based instruction.

\section{REFERENCES}

Barr, R. B., \& Tagg, J. (1995). From teaching to learning-A new paradigm for undergraduate education. Change, 27, 18-25.

Bonwell, C. C., \& Eison, J. A. (1991). Active learning: Creating excitement in the classroom. Washington DC: George Washington University.

Dewey, J. (1933). How we think: A restatement of the relation of reflective thinking to the educative process. Lexington, MA: D. C. Heath and Company.

Dewey, J. (1944). Democracy and education: An introduction to the philosophy of education. New York, NY: The Free Press.

Felder, R. M. (1994). Any questions? Chemical Engineering Education, 28, 174-175.

I-Clicker (2011). The decision is simple. URL (last checked 11 July 2011). http:/www.iclicker.com/dnn/Abouticlicker/AdvantagesBenefits/tabi d/145/Default.aspx

Derek Bok Center (2007). Interactive teaching DVD: Promoting better learning using peer instruction and just-in-time teaching. Boston, MA: Addison-Wesley.

Johnson, D. W., \& Johnson, F. (2001). Joining together: Group theory and group skills (4th ed.). Englewood Cliffs, NJ: Prentice Hall.

Johnson, D. W., Johnson, R. T., \& Smith, K. A. (1998). Active learning: cooperation in the college classroom (2nd ed.). Edina, MN: Interaction Press.

Johnson, D. W., Johnson, R. T., \& Smith, K. A. (1991). Active learning: cooperation in the college classroom. Edina, MN: Interaction Book Company.

Johnson, D. W., Johnson, R. T. \& Smith, K. A. (1998). Maximizing instruction through cooperative learning. ASEE Prism, 7, 24-29.

Lyman, F. T. (1998). The responsive classroom discussion: The inclusion of all students. In A. Anderson (Ed.), Mainstreaming Digest (pp. 109-113). College Park: University of Maryland Press.

Matin, M. A., \& Edelstein, J. (2008). Clicker: A personal response system for effective teaching. Proceedings of International Conference on Technology, Communication and Education, Kuwait, 7-9 April 2008, 48-50.

Macmillan News (2011). Move adds leading college custom publisher to macmillan portfolio. URL (last checked 12 July 2011). http://us.macmillan.com/splash/news/news07.html

McKeachie, W. (1999). Teaching tips (10th ed.). Boston, MA: Houghton Mifflin.

Mazur Group (2011). Peer instruction. URL (last checked 12 July 2011). http://mazur-www.harvard.edu/research/detailspage.php?rowid=8

Meyers, C., \& Jones, T. B. (1993). Promoting active learning. San Francisco, CA: Jossey-Bass.

Scott, M. (2007). Innovations in undergraduate physics education at Illinois. URL (last checked 12 July 2011). http://research.physics.uiuc.edu/ PER/Course_Revisions.html

Turning Technologies, LLC (2011). Turning ideas into solutions. URL (last checked 12 July 2011). www.turningtechnologies.com 